\title{
ENTREVISTA
}

\section{Maria Nélida Gonzalez de Gomez}

Maria Nélida Gonzalez de Gomez é reconhecida como uma das pesquisadoras mais influentes e produtivas no universo dos estudos interdisciplinares, políticos e culturais da informação no Brasil. Sua ênfase esta nas abordagens epistemológicas e nas constelações teóricas da Ciência da informação, no contexto das Ciências Humanas e Sociais. Atualmente desenvolve pesquisa vinculada aos seguintes projetos: "Da validade do conhecimento à validade da informação" e "Os caminhos da informação. Questões, ações e pensamentos". Maria Nélida nasceu na Argentina, fez sua graduação em Filosofia na Universidad Nacional de Rosário e posteriormente, desenvolveu sua carreira acadêmica no campo da Ciência da informação no Brasil. É Mestre em Ciência da Informação pelo Programa de Pós-graduação do IBICT - UFRJ (Instituto Brasileiro de Informação em Ciência e Tecnologia Universidade Federal do Rio de Janeiro) e Doutora em Comunicação pela UFRJ. Atualmente é docente junto ao Programa de Pós-graduação em Ciência da Informação, convênio UFRJIBICT. Atualmente ministra disciplinas sobre Teoria e história da informação; Epistemologia da Ciência da Informação; Pensamento contemporâneo e questões de informação e é e Bolsista Produtividade CNPQ, IA. Atuou como Coordenadora do Programa de Pós-graduação em Ciência da Informação, IBICT-UFRJ, 1998-2000 e foi representante da área de Ciência da Informação no Comitê de Comunicação, Ciência da Informação e Arte, no Conselho Nacional de Pesquisa-CNPq, de 2008 à 2011. Tem em seu histórico de orientações de Mestrados e Doutorados, mais de 50 trabalhos, além de 4 pós doutorados, estando 2 em andamento. Organizou e colaborou na produção dos seguintes Livros: "Informação e democracia: a reflexão contemporânea da ética e da política"; "Linguagem, informação e novas dinâmicas sociais contemporâneas"”; "Políticas de Memória e Informação: reflexos na Organização do Conhecimento" e "Política e gestão da informação", além de co-produzir Material didático multimídia: Inclusão digital e aprendizagem informacional. Produziu mais de 70 publicações distribuídas entre artigos de revistas, capítulos de livros e trabalhos completos em Anais de eventos, nacionais e internacionais, voltados aos estudos sobre a transversalidade e convergência cultural e tecnológica do mundo contemporâneo; em seus trabalhos analisa os

\footnotetext{
${ }^{1}$ Texto publicado na Liinc em Revista, Rio de Janeiro, v. 6, n. 2, set. 2010, p. 153-154. Disponível em: $<$ http://www.ibict.br/liinc>
}

InCID: R. Ci. Inf. e Doc., Ribeirão Preto, v. 3, n.1, p. 172-181, jan./jun. 2012. 
efeitos disto sobre as questões políticas, éticas e epistemológicas da informação, em diferentes contextos sociais, tratando de temas como a inter e transdisciplinariedade, os critérios de validade da informação, os processos de argumentação, as políticas e regimes de informação. Explora os limites da Ciência da informação, alargando suas fronteiras e fortalecendo seus alicerces. Ter a professora Maria Nélida na sessão de entrevistas desta InCID é motivo de honra e orgulho para a USP-Ribeirão; suas palavras merecem ser ouvidas em português e espanhol, pois não são poucos seus leitores no mundo íbero-americano. Esta entrevista contou com a colaboração de Solange Puntel Mostafa e Luciana Gracioso.

InCID: Professora Nélida, esta sessão da revista InCid tenta aproximar os leitores de autores relevantes na literatura de ciência da informação; no seu caso, somos tomados pela dupla emoção de reconhecer a importância da sua contribuição no cenário latinoamericano da ciência da informação e, ao mesmo tempo, reconhecê-la colega, professora e orientadora de muitos leitores. Iniciemos por sua formação em filosofia: há algo que queira destacar na sua formação que a tenha aproximado ao campo de ciência da informação?

Maria Nélida: Agradeço o interesse da InCID; o trabalho de orientação tem sido desenvolvido com o maior respeito a vontade argumentativa dos autores, tratando de estimular a construção de bons argumentos, numa direção compartilhada de relevância; tenho acompanhado assim muitas pesquisas importantes e inovadoras.

Comecei a estudar filosofia sem saber que isso que me atraia chamava-se filosofia, Minha primeira aproximação foi uma coleção de livros das mais variadas e díspares abordagens, de Bacon à Avenarius, incluido um manual de Garcia Morente, presente de meu pai, professor, amigo dos livros e da leitura. Não sei como chegou a minhas mãos "Assim falava Zaratustra", de Nietzche, lí deslumbrada com o fato de alguém poder pensar e falar dessa maneira. Leitura de encantamento e ocultação, já que não era um autor aceito a mediados da década do 60. Só muito tempo depois me atrevi a falar que tinha lido Nietzche,.

Cheguei a faculdade de filosofia, a primeira, numa família de imigrantes, a frequentar a universidade, com a mais ingênua e imensa curiosidade. No terceiro ano de Faculdade, comecei a dar aulas como ajudante do Prof. Adolfo Carpio, na Universidade de Rosário, num prédio que já fora monastério, com um sucesso e entusiasmo próprio de uma época de 
convicções intelectuais fortes, sem dúvidas nem suspeitas. Platão e os modernos eram meus preferidos; autores como Hobbe e Locke eram exemplos paradigmáticos para entender a relação entre as cidades dos homens e as cidades das idéias, entre liberalismo e nominalismo, entre política e epistemologia. Com a intervenção da Universidade, trás um golpe militar, finalizada a graduação, passei três anos dando aulas de Filosofia e História da Cultura, na Universidade Estadual de Puerto Rico, em Arecibo. Naquele tempo, leituras de Homero, Sófocles, a descoberta de importantes obras críticas sobre religião e a literatura grega, me permitiam redescobrir Platão, Aristóteles, os pre-socráticos; ao mesmo tempo, me aproximava de Frankfurt, pela obra de Marcusse. Colegas da Universidade de Buenos Aires, com boa formação em literatura clássica e latino-americana, me ofereceram uma interlocução enriquecedora e uma rede protetora de afetos.

Decidi finalmente retornar a Argentina, para tratar de entender, de uma vez por todas, as vivencias de embate entre mundos ate então sem diálogo - da filosofia e da vida cotidiana, da filosofia e da política. Foram anos difíceis, mas intelectualmente ativos. A linguagem filosófica formal não me permitia estabelecer os novos diálogos dos quais sentia necessidade. Escolhi estudar mais sobre educação, teorias e fatos, comecei a fazer pesquisas pouco planejadas na Biblioteca Pública da Plaza Pringles, em Rosário; tratava de reconstruir memórias nos jornais incompletos, censurados; fazia anotações numa discreta livretinha de capas pretas emborrachadas; tempos de aprendizagem, de perdas e de encontros.

Com o retorno do governo representativo, retomei o trabalho como professora. Di aula de Introdução à Filosofia na Faculdade de Direito, e assumi uma consultoria em um projeto de educação. Trabalhei três anos numa equipe multidisciplinar de avaliação e planejamento curricular, no ensino primário, e percebi, alem das questões educacionais nelas mesmas, as dificuldades da construção de significados comuns em contextos híbridos de plurais saberes e experiências. Durante esse processo, montamos uma metodologia de consultas regulares, que incluíam professores de Ensino Elemental (Provincia de Santa Fe), e grupos de pais que representavam as diferentes comunidades locais a que serviam as escolas: os centros urbanos, o campo, as ilhas do Rio Paraná; a pluralidade de linguagens e saberes era muito grande, a aprendizagem foi insubstituível. Sem saber, já estava rumo aos estudos das mediações, do papel da comunicação e da informação na produção de conhecimentos, das epistemologias participativas, em fim, tratando de entender os trajetos e usos da linguagem na vida coletiva. Nunca mais conseguiria separar a linguagem, as pessoas e seus contextos de ação. Sentia que 
eu mesma precisaria ainda encontrar outras linguagens, para juntar tudo isso, narrar essas experiências.

Novo golpe militar, já com um filho, casada, os próximos passos tinham que ser decididos a dois ou a três. E o decidido, por razões de trabalho do pai de meu filho, foi Brasil.

Chegando a Brasil, consegui retomar os estudos, agora em Ciência da Informação, eu suspeitava, ainda que sem certeza, que lá encontraria novos caminhos.

De novo na pesquisa e na docência, o trabalho com os alunos permitia ir abrindo trilhas em direção a novos questões e em direção aos saberes do Brasil, tão desafiantes, tão complexos, tão envolventes. Como ficará claro nas lembranças que seguem, muitos diálogos acompanharam esse percurso de mais de trinta anos, nomear a todos os pesquisadores e profissionais brasileiros com os quais aprendi e compartilhei aprendizagens, levaria muitas paginas. Nomeio, assim, somente alguns dos primeiros, Jandira Baptista, Hagar Espanha, Rosali Fernandez, completaram e alargaram o sentido de duas palavras ditas por Antonio Miranda num corredor do IBICT, sobre a ação documentária : "controle-acesso".

Naqueles tempos, porem, já não conseguiria volver a meus livros de filosofia com a mesma inocência de minha juventude. Posso pensar hoje que meu verdadeiro exílio, já antes de chegar ao Brasil, foi praticar uma filosofia de diáspora, fora dos lugares formais de minhas vivencias juvenis, lugares específicos onde a filosofia era legitimada, e onde minhas inquietações encontraram tão boa acolhida. Foi, ao mesmo tempo, talvez, minha verdadeira iniciação filosófica, ao ter que pensar filosoficamente aquilo que, por suas atribuições imediatas e por sua condição, não se apresentava investido das categorias do discurso filosófico, mas das categorias da administração curricular de um sistema escolar, dos modelos de supervisão e avaliação educativa, e logo, como teorias e modelos de organização do conhecimento, na forma de questões acerca de bibliotecas, arquivos, periódicos, políticas e sistemas de informação.

Os primeiros nexos entre a filosofia e a Ciência da Informação, foram estabelecidos com a Teoria da Classificação, as leituras de Austin e do Precis ${ }^{2}$, Ranganathan, Farradane. Operações, relações, categorias, me ajudavam a identificar qual o lugar onde devia ancorar minhas perguntas.

\footnotetext{
${ }^{2}$ Abreviatura de Preserved Context Index System
}

InCID: R. Ci. Inf. e Doc., Ribeirão Preto, v. 3, n.1, p. 172-181, jan./jun. 2012. 
Parecia ser que se esse era o "modus cognoscendi", precisava, agora, ir além do sistema de informação e das organizações específicas de informação documentária (especificamente arquivos e bibliotecas) trazer-los "fora-de-si" para re-encontrar-lhes, em seu ser "para-ohomem", porque é pelo estranhamento como o homem consegue entender suas obras. Foram assim dois movimentos sincrônicos, da indagação filosófica às práticas de produção comunicativa dos conhecimentos (educacionais, informacionais, documentárias), e das práticas infocomunicacionais aos programas político-epistêmicos em que estão inseridas. Com a informação, o conhecimento e a linguagem teriam um enclave em programas coletivos de ação, situados num mundo. Tratava-se, então, de seguir os caminhos da informação, entre as ONGs e o Estado, as escolas e o trabalho, a cidade e a universidade, a saúde e a estatística, as ciências e as artes. Hoje me pergunto pelas regras e construções valorativas acerca de documentos e informações, entretecidas nesses meandros das linguagens e da ação.

Posso falar, finalmente, de uma epistemologia política da informação, uma epistemologia que é do sur, não porque se nomeia do sur, é porque cresce, como as ervas silvestres, nos interstícios que lhe deixam as dificuldades da vida.

InCID: Seu texto Para uma reflexão epistemológica acerca da ciência da informação (2001) constitui-se, como muitos outros de sua autoria, em um quase programa de estudos para qualquer interessado em questões epistemológicas, em que o saber humanístico como a filosofia e a história comparecem como os primeiros discursos sobre a ciência enquanto que os saberes estratégicos e de monitoramento promovidos pela administração e quiçá pela economia, seriam os mais contemporâneos. A professora gostaria de se estender mais sobre estes últimos saberes estratégicos atuais?

Maria Nélida: Em minhas pesquisas, achei prudente construir um conceito analítico, o de regime de informação, para dar visibilidade a aquilo que manifestando-se como sendo da ordem da informação, remetia as vinculações, de modo seletivo e preferencial, de atores, ações, meios, contextos e conteúdos. Fui re-encontrando o termo, usado brevemente por Frohmann, com inspiração foucaultiana, em Braman, Ekbia, Simondon e Giddens. O certo é que através dessa ferramenta conceitual comecei a perceber o deslocamento da prioridade e relevância das questões e ações de informação, centradas previamente no Estado, para dar ênfase às organizações e aos mercados. Para entender isso, incorporei leituras da economia da informação e do capitalismo cognitivo; os estudos sociológicos da economia, como os de

InCID: R. Ci. Inf. e Doc., Ribeirão Preto, v. 3, n.1, p. 172-181, jan./jun. 2012. 
Callon e de Marazzi, me pareceram bastante produtivos, nessa direção da busca de entendimento.

Entre os passos para mim importantes, dados nessa direção, foi entender que a incorporação de questões e noções de informação, não implicava necessariamente uma ruptura paradigmática com as grandes premissas da economia capitalista, das quais muitas aplaudidas abordagens eram reformulações. Por outro lado, uma leitura cruzada de Bourdieu e de Braman me instigaram a buscar certas linhas de passagem e continuidade, do conceito de capital intelectual ao de capitalismo cognitivo, com um potencial crítico que tal vez possa estender-se em outras direções.

Minhas recentes leituras de publicações periódicas de Administração, Economia, Comunicação e Ciência da Informação, me tem levado a revalorizar o papel da dimensão tecnológica e elaborar uma hipótese, sujeita a teste, mas bastante plausível: considerando as diferenças de configuração e investimento teórico-epistemológico, poderíamos afirmar que

- Nos discursos da Ciência da Informação e da Comunicação, as tecnologias de comunicação e informação aparecem como variáveis causais ou independentes, de efeito teleológico sobre os modos e programas de ação;

- Na Administração e na Economia, porem, as TICS são consideradas como variáveis dependentes, a serem incorporadas, e por isso, controladas e apropriadas, pelas firmas e organizações e pelos mercados. O caráter necessário ou iminente dessa incorporação não transformaria, porem, as tecnologias de comunicação e informação, num ponteiro a indicar a direção e qualidade das metas e dos investimentos.

Será um erro de percepção ao que fui induzida pela seleção dos textos lidos e analisados, provenientes de revistas científicas, a circular em esferas acadêmicas, no Brasil? Fica, então, a questão.

Penso, aliás, que a última questão não indica a direção das próximas questões, porque o que abre um novo horizonte do perguntar, não é a última pergunta, mas aqueles e aquilo que nos levaram a indagar. Pode ser o meio ambiente, a memória, regras e normas. 
INCID: Professora, é inevitável conversarmos aqui sobre o filósofo sobre o qual a senhora tem dedicado em várias oportunidades, Jurgues Habermas, em sua Ação comunicativa. Uma virada linguística iniciada por Wittegestein, ainda no começo do século vinte, com desdobramentos em John Austin (do lado inglês) e em John Searle (do lado americano), passando também pelo francês Oswald Ducrot, veríamos esses esforços da filosofia da linguagem acrescidos com mais um nome, que não lhe passou desapercebido: Jurges Habermas. Gostaríamos que comentasse as provocações de J-F Lyotard acerca do aspecto agonístico dos jogos de linguagem, bem como a crítica de Lyotard aos universalismos e ao consenso habermasiano.

Maria Nélida: Agonisticas são as histórias das pessoas, sujeitas ao desrespeito, à pobreza, ao desamor, à mortes postergáveis, ao estreitamento estrutural dos seus horizontes de vida. O conceito de jogo de linguagem nos leva a sentir a contingencialidade dessa agonística, que neles se manifesta como local e reversível, assim como neles se manifestam jogos de imaginação e de alegria, também locais, presentes e plausíveis. Não é porem a resposta a todas as perguntas. As Investigações Filosóficas de Wittgenstein são como um reagente para desnaturalizar figuras de discurso: um fio de Ariadna para enfrentar a contingência sem extravios, para pensar a céu aberto, sem aquele guarda-chuva com que os modernos se protegiam do espaço infindável, na fala de Deleuze. A noção de informação, aliás, introduz essa contingencialidade nas ilusões da estrutura, assim como temporaliza a esperança da perfeita communio.

Enquanto a Habermas, meu interesse inicial era por sua concepção da pragmática formal. A denominação de Pragmática Formal, em vez de Pragmática Universal, teria que ver com a passagem de um estudo que partia dos usos da linguagem (empiria) a uma reconstrução das condições dos usos da linguagem (reconstrução formal, de um ponto de vista "socio-logico"). Habermas retoma o tema da dupla estrutura da fala no livro Teorída de la acción comunicativa: Complementos y estudios prévios, publicado pela Cátedra de Madrid: "En una perspectiva genética este carácter invariante de los contenidos proposicionales se presenta como uma desconexion de componente ilocucionario y componente proposicional em la formación y transformación de actos de fala. Esta desconexión es condición para la diferenciación de la doble estructura del habla, es decir, para la separación de dos niveles de la comunicación em los que hablante y oyente han de entenderse simultaneamente si quieren comunicar mutuamente sus intenciones." (Habermas, 1994, 341). Essa dupla articulação da linguagem permitiria sustentar a dupla articulação da produção informacional do sentido, 
informação e meta-informação; dependeria assim de uma condição linguística e de uma inovação social, que tinha gerado uma divisão do trabalho linguístico.

Esse pensamento e construção acontecia na época do diálogo cruzado entre Solange Puntel Mostafa, Miguel Angel Rendon Rojas, Ana Maria Marques Cintra, do qual tive a sorte de participar.

Por outro lado, e entrando já na Teoria da Ação Comunicativa, considero que a agonística está no ponto de partida do pensamento de Habermas, onde a mínima unidade de análise é a relação ego-alter, sempre presente e sempre ameaçada. Ele pergunta, porem, com seu otimismo humanista, como em meio de tanta fragilidade, tantos empecilhos e catástrofes, podemos realizar programas coletivos de ação, buscar em comum o entendimento, tecer vínculos de solidariedade. Pergunta desde Europa, um perguntar europeu, mas num novo cenário de mundialização, onde o outro hoje pode ter qualquer rosto, qualquer etnia, qualquer marca de exclusão. Para mim, ele pensa numa moral que sustente os direitos de qualquer um. Lidaria, por isso, com uma demanda de universalidade ao avesso, não a universalidade do contrato ideal, mas aquela que parte de uma negação que nos iguala, estar em comum confrontados à ausência do contrato natural; uma das figuras contemporâneas da afirmação, ao mesmo tempo, dos direitos à igualdade e à diferença.

Não me sento habermaseana, porém; uma teoria ou escola são guias temporais da busca de entendimento, temos que poder ser infiéis aos autores para não atropelar as exigências da vida e o rigor do pensamento.

\section{InCID: Uma outra questão diz respeito ao GT 1 do ENANCIB. A senhora poderia fazer uma avaliação das contribuições nesse gt bem como um breve balanço da epistemologia da ciência da informação no Brasil, se isto for pertinente?}

Maria Nélida: O GT1 do ENANCIB tem sido um laboratório de exposição e aferimento de todas as tendências e linhas de pesquisa com que, no Brasil, temos explorado, sob a metáfora da informação, a comunicação científica, as epistemologias cidadãs, as novas interfaces documentario-tecnológicas de museus, arquivos, bibliotecas, centros de documentação- em fim, os eventos ditos de informação como eventos sociais e epistêmicos. As participações transitórias dos pesquisadores, que tem caracterizado este GT, fizeram dele um Forum de diversos, antes que um Conselho paradigmático. A meu ver, isso tem sido positivo.

InCID: R. Ci. Inf. e Doc., Ribeirão Preto, v. 3, n.1, p. 172-181, jan./jun. 2012. 
Se os regimes de informação são como um Observatório privilegiado das sociedades contemporâneas, os estudos socio-epistemológicos em Ciência da Informação são um dos instrumentos mais interessantes desse observatório, porque permitem desmistificar abordagens unidirecionais dos cenários atuais da informação. Ao mesmo tempo, a presença de autores que tinham como temas principais a organização do conhecimento, a política, a economia e a gestão da informação, tem permitido ponderar as abordagens internalistas da comunicação documentário-informacional formalizada, por vezes redutoras do seu papel e participação nas diferentes esferas da vida social.

Logos, antes que a reflexão, o hibridismo dos fóruns epistemológicos tem, para mim, uma função crítica e heurística, de exercício da imaginação linguística, do pluralismo com diálogo e comprometimento.

Pensar na informação como Commons, por exemplo, permite trazer para a discussão contemporânea a composição e gestão dos ensambles de documentos, artefatos e informações (coleção, fundos, acervos, patrimônio) ou os novos "patronatos" das memórias coletivas (dos Museus de griffe ao Facebook). Ao mesmo tempo, entender os commons informacionais requer ir alem dos limites de algumas abordagens da propriedade intelectual e do acesso aberto, quando são colocados fora da discussão as questões sobre a pre-interpretação cultural dos conteúdos ou os direitos narrativos das pessoas sobre suas próprias vivencias cotidianas.

Um dos papeis principais do GT1 da ENANCIB, seria, acredito, ter conseguido manter abertas as portas argumentativas para questões novas e tradicionais; cabem outras questões e tarefas aos outros GTs.

InCID: Por fim gostaríamos de relembrar, num emocionante final do artigo publicada na revista Datagramazero, sobre metodologia da ciência da informação, no qual a professora Nélida traz em sua memória, a literatura americana: Gabriel Garcia Marquez, Machado de Assis, Proust, Whalt Whitman e Allan Poe; haveria caminhos para aproximarmos a literatura da ciência da informação? Arte e ciência?

Maria Nélida: Os livros, a literatura, tem sido interlocutores permanentes, desde minha infância; Monteiro Lobato foi minha primeira descoberta do Brasil, sem sentimentos de fronteira: ele falava a língua de minha curiosidade e de minha fantasia. 
O barbeiro do povoadinho onde nasci, tinha um único livro, de Espinoza, e com ele interpretava todo o que acontecia no seu dia a dia. Não entendia ainda de espinozismo, mas achava que tinham que ser mais de um livro, ao menos uma enciclopédia, uma biblioteca, todas as livrarias. Tenho passado muitas horas de minha vida em bibliotecas públicas e universitárias, elas são minhas casas. Hoje passo muitas horas na Internet, mas a Internet não é uma de minhas casas, é um transporte.

A literatura e o conhecimento científico são caminhos paralelos, que por vezes se cruzam e podem algumas vezes serem indiscerníveis, mas na dispersão, plurificam a aventura humana, com todo o vigor de suas potencialidades diferenciais.

As afeições tem intensidade difíceis de alcançar pelos conceitos. A arte religiosa popular, como o funeral de uma criança vestida de anjinho, comove de entrada mais que uma cifra epidemiológica sobre a mortalidade infantil da pobreza. O interessante é conseguir passar dos afetos aos conceitos, e vice-versa, para que experiências como as da epidemiologia e da arte sirvam para mobilizar-nos desde a dor em direção à hominização da espécie. 